Check for updates

Cite this: RSC Adv., 2018, 8, 30512

Received 24th July 2018

Accepted 21st August 2018

DOI: 10.1039/c8ra06260a

rsc.li/rsc-advances

\section{Enhanced production of optical (S)-acetoin by a recombinant Escherichia coli whole-cell biocatalyst with NADH regeneration $\uparrow$}

\author{
Jian-Xiu Li, (DD ab Yan-Yan Huang, ${ }^{\mathrm{b}}$ Xian-Rui Chen, ${ }^{\mathrm{b}}$ Qi-Shi Du, ${ }^{\mathrm{D}}{ }^{\mathrm{b}}$ Jian-Zong Meng, ${ }^{\mathrm{a}}$ \\ Neng-Zhong Xie (iD) *b and Ri-Bo Huang*ab
}

\begin{abstract}
Acetoin is an important platform chemical with a variety of applications in foods, cosmetics, chemical synthesis, and especially in the asymmetric synthesis of optically active pharmaceuticals. It is also a useful breath biomarker for early lung cancer diagnosis. In order to enhance production of optical (S)acetoin and facilitate this building block for a series of chiral pharmaceuticals derivatives, we have developed a systematic approach using in situ-NADH regeneration systems and promising diacetyl reductase. Under optimal conditions, we have obtained $52.9 \mathrm{~g} \mathrm{~L}^{-1}$ of $(S)$-acetoin with an enantiomeric purity of $99.5 \%$ and a productivity of $6.2 \mathrm{~g}(\mathrm{~L} \mathrm{~h})^{-1}$. The results reported in this study demonstrated that the production of (S)-acetoin could be effectively improved through the engineering of cofactor regeneration with promising diacetyl reductase. The systematic approach developed in this study could also be applied to synthesize other optically active $\alpha$-hydroxy ketones, which may provide valuable benefits for the study of drug development.
\end{abstract}

\section{Introduction}

Enantiomeric $\alpha$-hydroxy ketones are important pharmaceutical intermediates, widely applied in antifungal agents, antitumor antibiotics, antidepressants, farnesyl transferase inhibitors and selective inhibitors of amyloid- $\beta$ protein production. ${ }^{1-3}$ Acetoin (3-hydroxy-2-butanone), the smallest natural chiral $\alpha$-hydroxy ketone, is a popular flavor additive, preservative, plant growth promoter and breath biomarker of early lung cancer, and is identified as one of the top 30 potential building blocks. ${ }^{4-7}$ This four-carbon compound has one chiral center in the molecule and therefore exists as two stereoisomers, $(R)$-acetoin and $(S)$ acetoin. ${ }^{\mathbf{8} 9}$ With FEMA no. 2008, acetoin is a substance generally recognized as safe (visit https://ntp.niehs.nih.gov/ for toxicity and related information). Acetoin and its isomers are widely applied in foods, cosmetics, chemical synthesis, especially in asymmetric synthesis of optically active pharmaceuticals and liquid crystals. $^{\mathbf{1 0 , 1 1}}$ Its derivate, 4-chloro-4,5-dimethyl-1,3dioxolan-2-one, has been extensively utilized in modifying

\footnotetext{
${ }^{a}$ State Key Laboratory for Conservation and Utilization of Subtropical Agro-Bioresources, Life Science and Biotechnology College, Guangxi University, 100 Daxue Road, Nanning, 530004, China. E-mail: xienengzhong@gxas.cn; guruace@ 163. com

${ }^{b}$ State Key Laboratory of No-Food Biomass and Enzyme Technology, National Engineering Research Center for No-Food Biorefinery, Guangxi Key Laboratory of Biorefinery, Guangxi Academy of Sciences, 98 Daling Road, Nanning, 530007, China $\uparrow$ Electronic supplementary information (ESI) available. See DOI: 10.1039/c8ra06260a
}

antibiotics to synthesize optically active drugs, which could enhance drug targeting properties and reduce side effects. ${ }^{\mathbf{1 2 , 1 3}}$

Native microorganisms generally produce acetoin as a mixture of two stereoisomers, in which $(R)$-acetoin is predominant and $(S)$-acetoin exists as a minor by-product, leading to very low yield of $(S)$-acetoin and high cost of chiral separation. ${ }^{14-16}$ Liu et al. developed an engineered Lactococcus lactis to produce $(S)$-acetoin from glucose. ${ }^{17}$ However, the nonenzymatic oxidative decarboxylation of $\alpha$-acetolactate to diacetyl occurred spontaneously and inefficiently, the engineered strain could only produce $5.8 \mathrm{~g} \mathrm{~L}^{-1}$ of $(S)$-acetoin with a productivity of $0.19 \mathrm{~g}(\mathrm{~L} \mathrm{~h})^{-1}$. Several attempts to produce $(S)$ acetoin by using purified enzymes have been reported previously. According to Loschonsky et al., cyclohexane-1,2-dione hydrolase formed $(S)$-acetoin with a $95 \%$ enantiomeric excess from $23 \mathrm{mM}$ substrate by homocoupling of acetaldehyde. ${ }^{18}$ In 2013, Gao et al. developed a two-enzymes coupling system, in which NADPH-dependent carbonyl reductase reduced diacetyl to produce $(S)$-acetoin, and glucose dehydrogenase was used to regenerate NADPH. Under optimal conditions, $12.2 \mathrm{~g} \mathrm{~L}^{-1}$ of $(S)$ acetoin (enantiomeric purity: 96.9\%) with a productivity of $9.8 \mathrm{~g}$ $(\mathrm{L} \mathrm{h})^{-1}$ was produced. ${ }^{\mathbf{1 9}}$

Recently, recombinant whole-cells have emerged as biocatalysts for $(S)$-acetoin production. He et al. ${ }^{20}$ described a wholecell biocatalytic process with a high yield by recombinant $E$. coli cells co-expressing $(2 R, 3 R)-2,3$-butanediol dehydrogenase $(R, R$ $\mathrm{BDH}), \mathrm{NADH}$ oxidase and hemoglobin. The recombinant strain produced $72.4 \mathrm{~g} \mathrm{~L}^{-1}(S)$-acetoin from a mixtures of 2,3-butanediol isomers. However, the enantiomeric purity of the product was 
only $94.7 \%$ for the generation of $(R)$-acetoin. Since $(S)$-acetoin can be used to provide chiral groups in high-value pharmaceuticals or for liquid crystals, high optical purity (i.e., over 98.0\%) is particularly required. Gao et al. developed a whole-cell biocatalytic process for $(S)$-acetoin production by over-expressing diacetyl reductase (DAR) in E. coli. ${ }^{12}$ When diacetyl and glucose were used as substrate and co-substrate respectively, the recombinant whole-cells could produce $39.4 \mathrm{~g} \mathrm{~L}^{-1}$ of $(S)$-acetoin in $20 \mathrm{~h}$. Since diacetyl is a prochiral compound that can be produced by chemical synthesis or microbial fermentation, it is a preferred substrate for optical $(S)$-acetoin. ${ }^{\mathbf{1 2 , 1 9 , 2 1 , 2 2}}$ However, two problems still need to be solved. First, due to the high concentration of intracellular DAR, the endogenous cofactor regeneration system of $E$. coli is typically not sufficiently efficient, ${ }^{23,24}$ limiting the titer and productivity of $(S)$-acetoin; second, organic acids (e.g. acetic acid and lactic acid) produced during glucose metabolism make product recovery difficult and increase glucose consumption. ${ }^{25}$

In this study, an efficient and economical process was developed for optical $(S)$-acetoin production from diacetyl. As shown in Fig. 1, two in situ-NADH regeneration systems were introduced into $E$. coli and determined their effectiveness in $(S)$-acetoin production. DAR genes from several species were codon-optimized and over-expressed to screen for a promising DAR with high stereoselectivity, specific activity and stability. Finally, a series of whole-cell biocatalytic reactions were performed to achieve high $(S)$-acetoin production.

\section{Materials and methods}

\subsection{Chemicals}

(2S,3S)-2,3-Butanediol (99.0\%) and meso-2,3-butanediol (98.0\%) were obtained from ACROS (Geel, Belgium). (2R,3R)-2,3-Butanediol $(97.0 \%)$, acetoin $(99.0 \%), \mathrm{NADH}$, and $\mathrm{NAD}^{+}$were obtained from Sigma (St Louis, USA). Diacetyl (99.0\%) was obtained from Aladdin (Shanghai, China). PCR primers were synthesized by Sangon (Shanghai, China) and DNA sequencing was performed by Genscript (Nanjing, China). Yeast extract and peptone were obtained from Oxoid (Hampshire, UK).

\subsection{Bacterial strains and vectors}

The strains and vectors used in the present study are listed in Table 1. E. coli $\mathrm{DH} 5 \alpha$ and $E$. coli BL21(DE3) were used for gene cloning and protein expressing, respectively. The pET-28a $(+)$ and pETDuet-1 were used for gene expression. Luria-Bertani medium $\left(10 \mathrm{~g} \mathrm{~L}^{-1}\right.$ peptone, $5 \mathrm{~g} \mathrm{~L}^{-1}$ yeast extract, and $10 \mathrm{~g} \mathrm{~L}^{-1} \mathrm{NaCl}$ at $\mathrm{pH}$ 7.0) was used for $E$. coli cultivation and solidified with $1.5 \%$ agar, if necessary. Kanamycin and ampicillin were used at concentrations of $30 \mu \mathrm{g} \mathrm{mL}^{-1}$ and $100 \mu \mathrm{g} \mathrm{mL} \mathrm{m}^{-1}$, respectively.

\subsection{Synthesis of DAR genes and construction of co- expression systems}

DNA manipulations were carried out using standard protocols. ${ }^{26}$ The codons for the DAR genes, Kpdar from K. pneumoniae

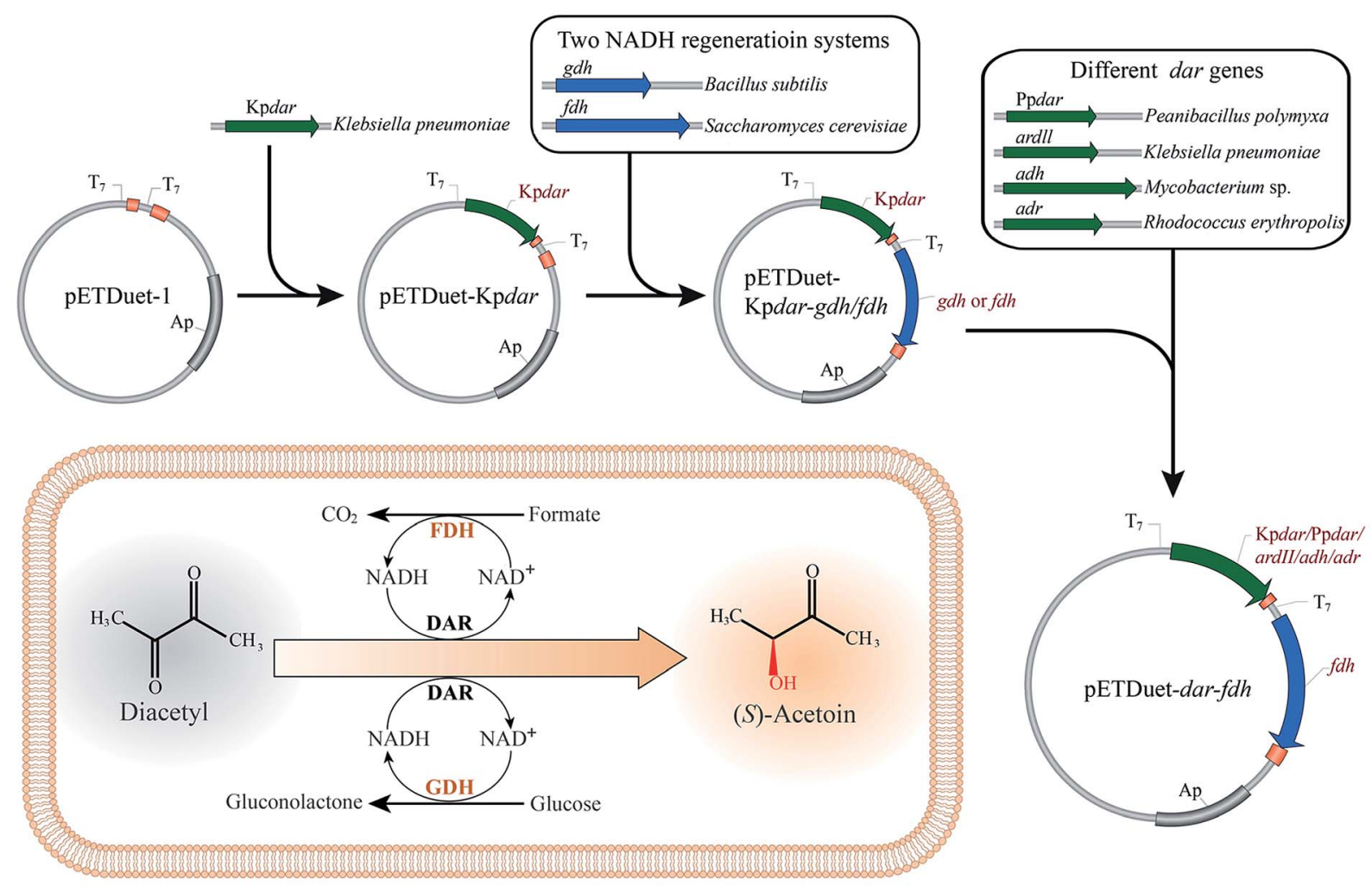

Fig. 1 Scheme for $(S)$-acetoin production from diacetyl using recombinant whole-cell biocatalysts with NADH regeneration systems. dar, the gene encoding diacetyl reductase (DAR); gdh, the gene encoding glucose dehydrogenase (GDH); fdh, the gene encoding formate dehydrogenase (FDH); Ap: the gene encoding ampicillin resistance. 
Table 1 Strains and plasmids used in this study

\begin{tabular}{lll}
\hline Strain and plasmid & Genotype and properties & $\begin{array}{l}\text { Source or } \\
\text { reference }\end{array}$ \\
\hline Strain & & \\
E.coli $\mathrm{DH} 5 \alpha$ & supE44 $\triangle$ lacU169 $(\varphi 80$ lacZ $\triangle$ M15) & Novagen \\
& hsdR17 recA1 endA1 & \\
& gyrA96 thi-1 relA1 & Novagen \\
E.coli BL21(DE3) & $F^{-}$ompT hsdSB $\left(\mathrm{rB}^{-} \mathrm{mB}^{-}\right)$ & \\
& gal $(\lambda \mathrm{c}$ I 857 ind1 Sam7 & \\
& nin5 lacUV5 T7gene1) dcm (DE3) &
\end{tabular}

Plasmid

pET-28a $(+)$ pETDuet- 1 pET-28a(+)-Kpdar pETDuet-fdh pETDuet-Kpdar pETDuet-Kpdar-gdh pETDuet-Kpdar-fdh pETDuet-Ppdar-fdh pETDuet-ard II- $f d h$ pETDuet-adh-fdh pETDuet-adr-fdh

Novagen Novagen This work This work This work This work

of the mixture was reacted in $100 \mathrm{mM}$ phosphate buffer $(\mathrm{pH} 7.5)$ at $32{ }^{\circ} \mathrm{C}$ and $200 \mathrm{rpm}$ for $2 \mathrm{~h}$. $(S)$-Acetoin production by wholecells co-expressing $f d h$ with DAR genes was carried out using $15.0 \mathrm{~g} \mathrm{~L}^{-1}$ of diacetyl and $12.0 \mathrm{~g} \mathrm{~L}^{-1}$ of formate (only account molecular mass of formate ion). For $(S)$-acetoin production by whole-cells co-expressing Kpdar with $g d h, 15.0 \mathrm{~g} \mathrm{~L}^{-1}$ of diacetyl and $30.0 \mathrm{~g} \mathrm{~L}^{-1}$ of glucose were required.

\subsection{Optimization of the reaction conditions}

To achieve a high conversion efficiency, the $\mathrm{pH}(5.5,6.0,6.5,7.0$, 7.5 , or 8.0$)$, temperature $\left(28{ }^{\circ} \mathrm{C}, 32{ }^{\circ} \mathrm{C}, 36{ }^{\circ} \mathrm{C}, 40{ }^{\circ} \mathrm{C}\right.$, or $\left.45^{\circ} \mathrm{C}\right)$, molar ratio of formate to diacetyl $(0.6,0.8,1.0,1.2,1.6$, or 2.0$)$, This work This work This work This work This work

CICC 10011 (GenBank accession no. HM113375.1), Ppdar from P. polymyxa DSM 365 (GenBank accession no. KT717931), ard II from K. pneumoniae 342 (GenBank accession no. CP000964.1), adh from Mycobacterium sp. B-009 (GenBank accession no. AB905197.1), and $a d r$ from $R$. erythropolis WZ010 (GenBank accession no. KC508606.1), were optimized and synthesized by Genscript (Nanjing, China), and then inserted into pETDuet-1 between the Nco I and Sac I sites to yield expression vectors. The formate dehydrogenase (FDH) gene fdh from $S$. cerevisiae (NCBI reference sequence NM_001183808.1), and Glucose dehydrogenase (GDH) gene gdh from B. subtilis (GenBank accession no. CP019663.1), were also synthesized with codon optimization. The $f d h$ and $g d h$ fragments were digested with Nde I and Kpn I, respectively. Then the fragments were ligated into the expression vectors that had been digested with the same restriction endonucleases. The co-expression plasmids were designated pETDuet-Kpdar-gdh, pETDuet-Kpdar-fdh, pETDuet-Ppdar-fdh, pETDuet-ard II- $f d h$, pETDuet- $a d h-f d h$, and pETDuet-adr-fdh, respectively.

\subsection{Biocatalyst preparation and bioconversion conditions}

The recombinant $E$. coli strains were cultivated at $37^{\circ} \mathrm{C}$ and $180 \mathrm{rpm}$ to $\mathrm{OD}_{600}$ of 0.6 . According to preliminary experiments, recombinant genes expression was induced with $0.2 \mathrm{mM}$ IPTG at $25{ }^{\circ} \mathrm{C}$ for $12 \mathrm{~h}$. The cells were harvested by centrifugation at $6000 \mathrm{rpm}$ and then washed twice with $0.85 \%$ $\mathrm{NaCl}$. The cell pellet was resuspended in $100 \mathrm{mM}$ phosphate buffer (pH 7.5) at a concentration of $20 \mathrm{~g}_{\text {(DCW) }} \mathrm{L}^{-1}$ and maintained at $4{ }^{\circ} \mathrm{C}$. The dry cell weight (DCW) of $E$. coli was determined by converting the $\mathrm{OD}_{600}$ value with a coefficient of 0.275 $\mathrm{g}_{\text {(DCW) }}$ per $\left(\mathrm{LOD}_{600}\right) .{ }^{27}$

A typical bioconversion reaction was carried out with 5.5 $\mathrm{g}_{\text {(DCW) }} \mathrm{L}^{-1}$ whole-cell biocatalyst in $50 \mathrm{~mL}$ flasks. A total of $10 \mathrm{~mL}$ and shaking speed (75 rpm, $100 \mathrm{rpm}, 125 \mathrm{rpm}, 150 \mathrm{rpm}$, or 175 $\mathrm{rpm}$ ) were investigated in turn. An initial bioconversion was reacted in $100 \mathrm{mM}$ phosphate buffer at $32{ }^{\circ} \mathrm{C}$ and $200 \mathrm{rpm}$ for $2 \mathrm{~h}$. The concentrations of cell, diacetyl and formate in the reaction was $5.5 \mathrm{~g}_{\text {(DCW) }} \mathrm{L}^{-1}, 15 \mathrm{~g} \mathrm{~L}^{-1}$ and $12 \mathrm{~g} \mathrm{~L}^{-1}$, respectively.

\subsection{Fed-batch biotransformation}

Fed-batch biotransformation was carried out in a $10 \mathrm{~mL}$ mixture at $40{ }^{\circ} \mathrm{C}$ and $125 \mathrm{rpm}$. The initial concentrations of diacetyl and whole-cell biocatalyst were $15.0 \mathrm{~g} \mathrm{~L}^{-1}$ and $5.5 \mathrm{~g}_{(\mathrm{DCW})} \mathrm{L}^{-1}$, respectively. The ratio of formate to diacetyl was 1.2 , and the $\mathrm{pH}$ was 6.5. During bioconversion, diacetyl was fed at intervals to maintain its concentration at 5.0-15.0 $\mathrm{g} \mathrm{L}^{-1}$, and $\mathrm{pH}$ was adjusted to 6.5 by formic acid. At the same time, small amounts of whole cell biocatalyst were added at the interval time, until the whole cell concentration reached to $11.0 \mathrm{~g}_{(\mathrm{DCW})} \mathrm{L}^{-1}$.

\subsection{Purification of KpDAR}

E. coli BL21(DE3) carrying plasmid pET-28a (+)-Kpdar was cultivated at $37{ }^{\circ} \mathrm{C}$ and $200 \mathrm{rpm}$ to $\mathrm{OD}_{600}$ of 0.6 , and then $0.4 \mathrm{mM}$ IPTG was added to the culture at $20^{\circ} \mathrm{C}$ for $12 \mathrm{~h}$. The culture was centrifuged at $6000 \mathrm{rpm}$, and the cell pellet was resuspended in buffer $(\mathrm{pH} 7.4 ; 20 \mathrm{mM}$ potassium phosphate, $500 \mathrm{mM}$ sodium chloride, $20 \mathrm{mM}$ imidazole, $1 \mathrm{mM}$ DTT, $0.1 \mathrm{mM}$ PMSF, and $10 \%$ glycerol). Cells were disrupted by sonication in an ice bath and centrifuged at $12000 \mathrm{rpm}$ for 30 min at $4{ }^{\circ} \mathrm{C}$. The Kpdar was purified by HisTrap HP column (GE Healthcare) and detected by SDS-PAGE.

\subsection{Assays for DARs, GDH and FDH activities}

Crude proteins were extracted from recombinant $E$. coli using BugBuster Master Mix reagent (Novagen). Enzyme activities were determined by monitoring the change in optical density at $340 \mathrm{~nm}$ corresponding to the reduction of $\mathrm{NAD}^{+}$or oxidation of $\mathrm{NADH}\left(\varepsilon_{340}=6.22 / \mathrm{mM} \mathrm{cm}\right)$ using a UV/visible spectrophotometer (DU800, Beckman). One unit of DAR activity was defined as the amount of enzyme that consumed $1 \mu \mathrm{mol}$ of NADH per min. The reaction mixture contained $5 \mathrm{mM}$ diacetyl and $0.2 \mathrm{mM}$ $\mathrm{NADH}$ in $100 \mathrm{mM}$ phosphate buffer (pH 6.5). One unit of GDH or FDH activity was defined as the amount of enzyme that produced $1 \mu \mathrm{mol}$ of $\mathrm{NADH}$ per min. The reaction mixture contained $5 \mathrm{mM}$ substrate (glucose or formate) and $0.2 \mathrm{mM} \mathrm{NAD}^{+}$in $100 \mathrm{mM}$ phosphate buffer ( $\mathrm{pH}$ 6.5). The reaction solution for the 
KPDAR reduction assay contained $5 \mathrm{mM}$ of ketone substrate and $0.2 \mathrm{mM}$ of $\mathrm{NADH}$ in $100 \mathrm{mM}$ phosphate buffer and for KpDAR oxidation contained $5 \mathrm{mM}$ of alcohol substrate and $0.2 \mathrm{mM}$ of $\mathrm{NAD}^{+}$in $100 \mathrm{mM}$ phosphate buffer. Protein concentrations were determined via the Bradford method using bovine serum albumin as a standard.

\subsection{Analytical methods}

The concentrations of diacetyl, acetoin, and 2,3-butanediol in the supernatant were determined using a gas chromatography (GC) system (Agilent 7890A) equipped with a polar column (Phenomenex ZB-WAX plus, $0.32 \mathrm{~mm} \times 0.25 \mu \mathrm{m} \times 30 \mathrm{~m}$ ). The injector and detector temperatures were both $250{ }^{\circ} \mathrm{C}$. The column oven temperature was maintained at $100{ }^{\circ} \mathrm{C}$ for $1 \mathrm{~min}$, then increased to $180{ }^{\circ} \mathrm{C}$ at a rate of $20{ }^{\circ} \mathrm{C} \mathrm{min}^{-1}$, finally maintained at $180{ }^{\circ} \mathrm{C}$ for $3 \mathrm{~min}$. $(R)$-Acetoin and $(S)$-acetoin in the supernatant were extracted using ethyl acetate and then measured by the GC system (Agilent 7890A) equipped with a chiral column (Agilent Cyclosil-B, $0.32 \mathrm{~mm} \times 0.25 \mu \mathrm{m} \times 30$ $\mathrm{m})$. The temperatures of injector and detector were both $240{ }^{\circ} \mathrm{C}$. The column oven temperature was maintained at $100{ }^{\circ} \mathrm{C}$ for $1 \mathrm{~min}$ and increased to $120^{\circ} \mathrm{C}$ at a rate of $10^{\circ} \mathrm{C} \mathrm{min}{ }^{-1}$. Then, it was increased to $130{ }^{\circ} \mathrm{C}$ at a rate of $6{ }^{\circ} \mathrm{C} \mathrm{min}$ minally to $^{-1}$ and finaty $230{ }^{\circ} \mathrm{C}$ at a rate of $20{ }^{\circ} \mathrm{C} \min ^{-1}$. The enantiomeric purity of $(S)$ acetoin was defined as $[\mathrm{S}] /([\mathrm{S}]+[\mathrm{R}]) \times 100 \%$, where $[\mathrm{R}]$ and $[\mathrm{S}]$ represented the concentrations of $(R)$-acetoin and $(S)$-acetoin, respectively. Formate and other organic acids concentration were analyzed using high-performance liquid chromatography (HPLC) system (Dionex UltiMate 3000) equipped with a Carbomix H-NP column (Sepax, $7.8 \times 300 \mathrm{~mm}$ ). The analysis was conducted at $55{ }^{\circ} \mathrm{C}$ with a mobile phase of $2.5 \mathrm{mM} \mathrm{H}_{2} \mathrm{SO}_{4}$ at a flow rate of $0.6 \mathrm{~mL} \mathrm{~min}^{-1}$.

\section{Results and discussion}

\subsection{Construction of different whole-cell biocatalysts by cofactor engineering}

Redox balance plays an important role for cell growth and cellular metabolism. ${ }^{28}$ When heterogeneous oxidoreductases are overexpressed, the endogenous cofactor regeneration system is typically not sufficiently efficient. ${ }^{23} \mathrm{GDH}$ and FDH are widely used for in situ-cofactor regeneration. ${ }^{25,29-31}$ To investigate their effect on $(S)$ acetoin production, $g d h$ gene from Bacillus subtilis $s^{32}$ and $f d h$ gene from Saccharomyces cerevisiae ${ }^{33}$ were synthesized after codon optimization (see ESI Table S1 $\dagger$ ) by GenScript (Nanjing, China) and co-expressed with DAR gene in E. coli BL21(DE3). To obtain a promising DAR, five DAR genes from several species were codon-optimized (see ESI Table S1 $\dagger$ ) and co-expressed with $f d h$ or $g d h$ to compare for $(S)$-acetoin synthesis. Recombinant DARs were detected by SDS-PAGE (see ESI Fig. S1†).

Batch biotransformation was conducted to evaluate the performance of two NADH regeneration systems with formate or glucose as co-substrate. As shown in Table 2, the conversion rate was low, obtained by $E$. coli BL21/pETDuet-Kpdar with single expression of KpDAR, and the final titer of $(S)$-acetoin was only $0.8 \mathrm{~g} \mathrm{~L}^{-1}$ with an enantiomeric purity of $89.3 \%$ and productivity of $0.4 \mathrm{~g}(\mathrm{~L} \mathrm{~h})^{-1}$. The crude extract enzyme of $E$. coli BL21/pETDuet-Kpdar-gdh showed a KpDAR activity of $33.4 \mathrm{U} \mathrm{mg}^{-1}$ and a GDH activity of $16.3 \mathrm{U} \mathrm{mg}^{-1}$. When introducing the GDH/ glucose system, the titer of $(S)$-acetoin increased to $4.3 \mathrm{~g} \mathrm{~L}^{-1}$ with an enantiomeric purity of $94.4 \%$ and productivity of $2.2 \mathrm{~g}$ (L h) ${ }^{-1}$ by $E$. coli BL21/pETDuet-Kpdar-gdh. Introduction of the $\mathrm{FDH} /$ formate system resulted in a higher $(S)$-acetoin titer, productivity and enantiomeric purity. $6.7 \mathrm{~g} \mathrm{~L}^{-1}$ of $(S)$-acetoin was obtained with an enantiomeric purity of $99.6 \%$ and productivity of $3.4 \mathrm{~g}(\mathrm{~L} \mathrm{~h})^{-1}$ by E. coli BL21/pETDuet-Kpdar-fdh. Crude extract of this recombinant strain showed a KpDAR activity of $34.9 \mathrm{U}$ $\mathrm{mg}^{-1}$ and a FDH activity of $0.45 \mathrm{U} \mathrm{mg}^{-1}$, while $E$. coli BL21/ pETDuet-Kpdar showed a KpDAR activity of $79.0 \mathrm{U} \mathrm{mg}^{-1}$.

Acetoin biosynthesis initiates with the condensation of two pyruvate molecules to yield one $\alpha$-acetolactate, then yield $(R)$ acetoin by decarboxylases or diacetyl upon spontaneous decarboxylation. ${ }^{24,34,35}$ Diacetyl can be further converted into $(R)$-acetoin or $(S)$-acetoin by DAR or BDH. Liang et al. reported that $E$. coli has an endogenous acetoin/2,3-butanediol pathway and glucose can be metabolized to acetoin by diacetyl-dependent endogenous system. ${ }^{24}$ In our study, the enantiomeric purity of $(S)$-acetoin produced by $E$. coli BL21/pETDuet-Kpdar-gdh with glucose as co-substrate was low $(94.4 \%)$, indicating that $(R)$ acetoin was produced by the intrinstic acetoin/2,3-butanediol pathway of $E$. coli. While in $\mathrm{FDH} /$ formate system, only a trace amount of $(R)$-acetoin was detected for the absence of glucose, and the enantiomeric purity of $(S)$-acetoin can reach to $99.6 \%$ by E. coli BL21/pETDuet-Kpdar-fdh.

Low-molecular-weight formate has similar price with glucose. Regeneration of $1 \mathrm{~mol}$ of NADH requires only $45 \mathrm{~g}$ of formate comparing $172 \mathrm{~g}$ of glucose, indicating that the reducing equivalent capacity of formate is approximately fourfold higher than that of glucose ${ }^{30}$ In addition, glucose can be metabolized to acetic acid, lactic acid by $E$. coli, further

Table 2 The products of batch bioconversion with different DARs and cofactor regeneration systems

\begin{tabular}{llll}
\hline Strain & $(S)$-Acetoin $\left(\mathrm{g} \mathrm{L}^{-1}\right)$ & Productivity $\left(\mathrm{g}(\mathrm{L} \mathrm{h})^{-1}\right)$ & Enantiomeric purity $(\%)$ \\
\hline E. coli BL21/pETDuet-Kpdar & $0.8 \pm 0.01$ & 0.4 & $89.3 \pm 0.97$ \\
E. coli BL21/pETDuet-Kpdar-gdh & $4.3 \pm 0.12$ & 2.2 & $94.4 \pm 0.79$ \\
E. coli BL21/pETDuet-Kpdar-fdh & $6.7 \pm 0.08$ & 3.4 & $99.6 \pm 0.08$ \\
E. coli BL21/pETDuet-Ppdar-fdh & $3.2 \pm 0.04$ & 1.6 & $95.9 \pm 0.77$ \\
E. coli BL21/pETDuet-ard II-fdh & $1.2 \pm 0.02$ & 0.6 & $54.5 \pm 0.07$ \\
E. coli BL21/pETDuet-adh-fdh & $1.8 \pm 0.03$ & 0.4 & $90.2 \pm 0.09$ \\
E. coli BL21/pETDuet- $a d r-f d h$ & $5.5 \pm 0.15$ & 2.8 & $98.5 \pm 0.19$
\end{tabular}


increasing glucose consumption. ${ }^{25} \mathrm{FDH}$ catalyses the conversion of formate to $\mathrm{CO}_{2}$ with no organic acid products, reducing the cost associated with the co-substrate and downstream processing. ${ }^{30,31,36}$ Considering the higher enantiomeric purity and titter, lower cost of the co-substrate, and easier purification, the $\mathrm{FDH} /$ formate system would significantly reduce total cost of $(S)$ acetoin production.

When co-expressing $f d h$ with other DAR genes including Ppdar, ard II, $a d r$, or $a d h$, all resulting biocatalysts produced $(S)$ acetoin, but the titer and enantiomeric purity of $(S)$-acetoin varied widely (Table 2). Because $E$. coli BL21/pETDuet-Kpdar-fdh showed the best performance in terms of both titer and enantiomeric purity among all recombinant strains, this strain together with KpDAR was used for subsequent analysis.

\subsection{Purification and characterization of KpDAR}

KpDAR was purified by Ni-affinity chromatography and confirmed by SDS-PAGE. The purified KPDAR showed single bands about $28 \mathrm{kDa}$ on the SDS-PAGE (see ESI Fig. S2 $\dagger$ ). Oxidation and reduction reactions were conducted to investigate the substrate specificities of KpDAR (see ESI Table S2 $\dagger$ ). KpDAR had clear activities towards diacetyl, $(R) /(S)$-acetoin and meso-2,3-butanediol with $\mathrm{NADH} / \mathrm{NAD}^{+}$as the cofactor. Diacetyl was the best substrate in the ketone reduction reactions. The specific activity of purified KPDAR towards diacetyl was up to $2887.6 \mathrm{U} \mathrm{mg}^{-1}$. meso-2,3-Butanediol was the best substrate in the alcohol oxidation reactions, while very low activity was observed with $(R) /(S)$-acetoin, $(2 S, 3 S)$-2,3-butanediol and $(2 R, 3 R)-2,3$-butanediol.

\subsection{Optimization of the reaction conditions}

The reaction conditions for $(S)$-acetoin production were optimized to increase the efficiency of the whole-cell biocatalysis. Because reaction $\mathrm{pH}$ and temperature are two important parameters that strongly influence enzyme activities and cellular maintenance, the effects of $\mathrm{pH}$ and temperature on whole-cell biocatalysis were first investigated. As shown in Fig. 2a, the titer (9.19 $\left.\mathrm{g} \mathrm{L}^{-1}\right)$ and yield (59.9\%) of $(S)$-acetoin was high at $\mathrm{pH}$ 6.5. Under more acidic or alkaline conditions, the yield of the transformation decreased. As shown in Fig. 2b, the optimal temperature was found at $40{ }^{\circ} \mathrm{C}$, and the yield of $(S)$ acetoin increased to $67.8 \%$.

The substrate specificities of KpDAR indicated that KpDAR not only showed a high catalytic efficiency toward diacetyl, but also exhibited acetoin reductase activity (see ESI Table S2 and Fig. S3 $\uparrow$ ). Both reductions of diacetyl and $(S)$-acetoin are accomplished with stoichiometric amounts of NADH consumption. Through manipulating the level of $\mathrm{NADH} / \mathrm{NAD}^{+}$,
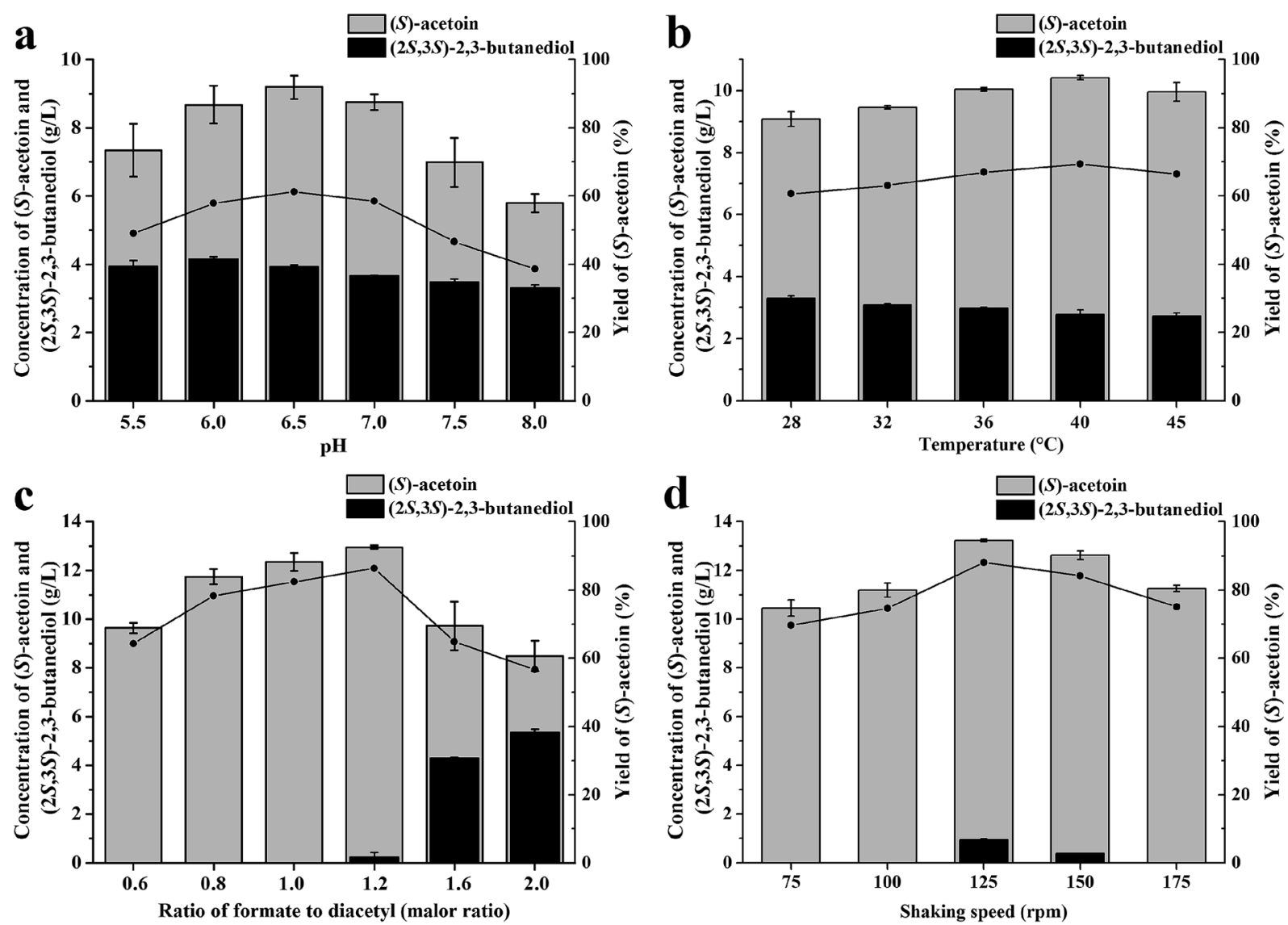

Fig. 2 Optimization of biocatalysis conditions. (a) pH; (b) temperature; (c) ratio of formate to diacetyl; (d) shaking speed. Error bars indicate standard deviations $(n=3)$. 

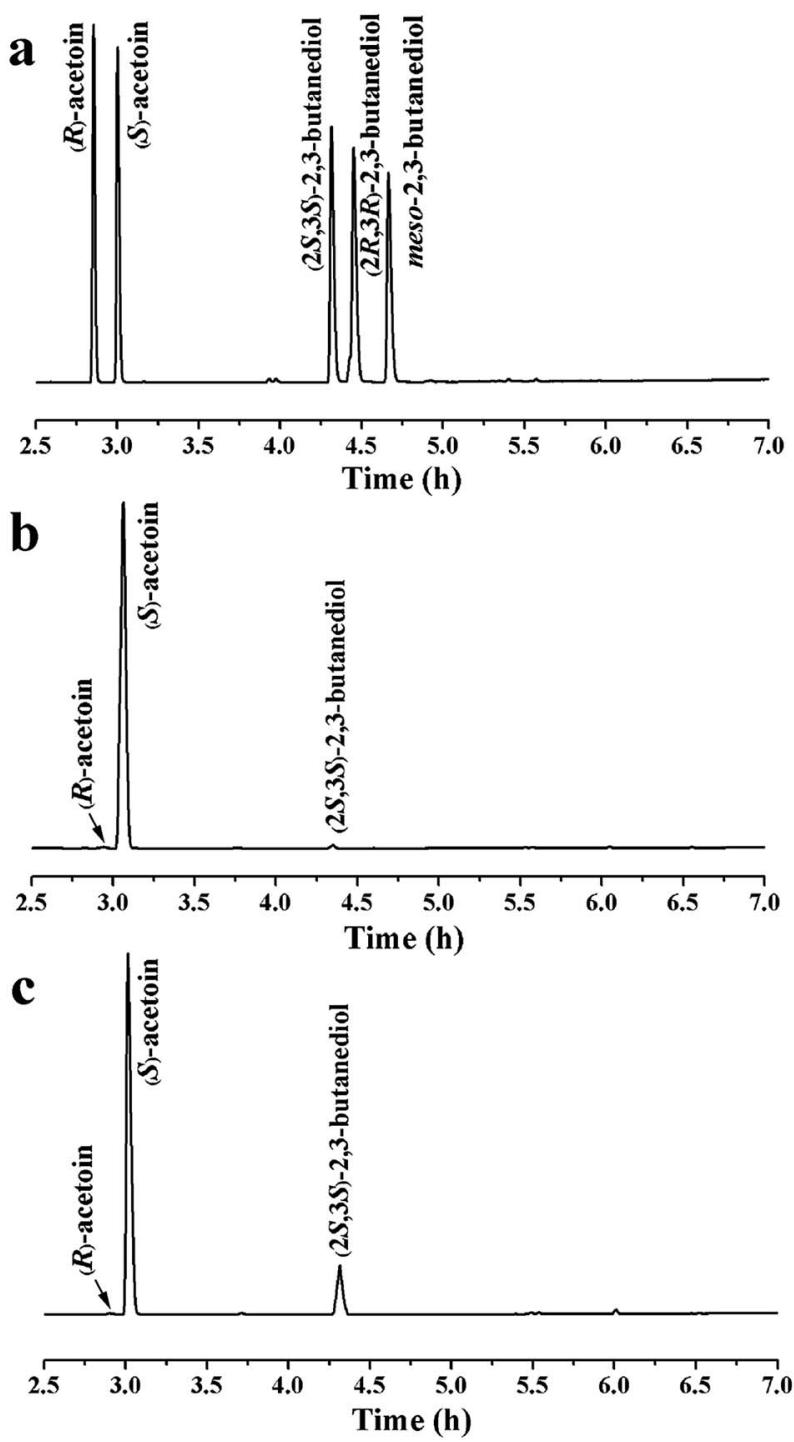

Fig. 3 Chiral-column GC analyses of products produced by wholecell of E. coli BL21/pETDuet-Kpdar-fdh. (a) Standard samples of pure stereoisomers; (b) sample from batch bioconversion by E. coli BL21/ pETDuet-Kpdar-fdh; (c) sample from fed-batch bioconversion by $E$. coli BL21/pETDuet-Kpdar-fdh. Samples were extracted using ethyl acetate and isoamyl alcohol was used as the internal standard.

production of $(S)$-acetoin can be improved..$^{25}$ Thus, to enhance $(S)$-acetoin production, the concentration of formate should be optimized. As shown in Fig. 2c, when the molar ratio of formate to diacetyl was low, increasing the concentration of formate effectively increased the efficiency of $(S)$-acetoin production. When the molar ratio was 1.2, $(S)$-acetoin production reached its maximum level $\left(12.96 \mathrm{~g} \mathrm{~L}^{-1}\right)$ with a yield of $84.4 \%$. Further increasing formate concentration to provide more NADH resulted in accumulation of $(2 S, 3 S)-2,3$-butanediol, thus decreased the final yield of $(S)$-acetoin.

Oxygen supply can significantly affect the ratio of NADH/ $\mathrm{NAD}^{+}$. Different oxygen supplies were investigated by varying the shaking speeds, and the optimal shaking speed was $125 \mathrm{rpm}$, as shown in Fig. 2d. Under optimal conditions, $13.2 \mathrm{~g}$
$\mathrm{L}^{-1}$ of $(S)$-acetoin was accumulated from $15.0 \mathrm{~g} \mathrm{~L}^{-1}$ of diacetyl with a productivity of $6.6 \mathrm{~g}(\mathrm{~L} \mathrm{~h})^{-1}$ (Fig. 2d). The yield of $(S)$ acetoin was $86.0 \%$ and the enantiomeric purity was $99.6 \%$ (Fig. 3a and b).

\subsection{Fed-batch biotransformation}

Diacetyl is toxic to recombinant $E$. coli, ${ }^{12,32}$ and therefore fedbatch processes should be performed to avoid substrate inhibition and achieve high product concentration. ${ }^{37}$ In this study, fed-batch biotransformation was conducted with an initial diacetyl concentration of $15.0 \mathrm{~g} \mathrm{~L}^{-1}$, while feeding small amounts of diacetyl and formate (ratio of formate to diacetyl approximately 1.2 ) at $1 \mathrm{~h}$ intervals. After $8.5 \mathrm{~h}$ of reaction, $52.9 \mathrm{~g}$ $\mathrm{L}^{-1}$ of $(S)$-acetoin was accumulated from $81.4 \mathrm{~g} \mathrm{~L}^{-1}$ of diacetyl with an enantiomeric purity of $99.5 \%$ (Fig. 3a and c) and productivity of $6.2 \mathrm{~g}(\mathrm{~L} \mathrm{~h})^{-1}$ (Fig. 4). The titer and productivity were new records on high optical $(S)$-acetoin (enantiomeric purity $\geq 98.0 \%$ ) production to our knowledge. In addition, $15.6 \mathrm{~g} \mathrm{~L}^{-1}$ of $(2 S, 3 S)-2,3$-butanediol was obtained (Fig. 4). It should be pointed out that this optical active compound is also a building block in the chiral synthesis, ${ }^{20}$ and could be separated from $(S)$-acetoin by distillation for their different boiling points. No meso-2,3-butanediol, $(2 R, 3 R)$-2,3-butanediol or organic acids were detected.

According to Liu et al., (S)-acetoin was effectively produced by biocatalytic resolution of the mixture of meso-2,3-butanediol and $(2 S, 3 S)-2,3$-butanediol by the resting cells of B. subtilis 168 , in which meso-2,3-butanediol was converted to $(S)$-acetoin. ${ }^{38}$ However, the enantiomeric purity of the product $(S)$-acetoin was low (96.2\%) for the generation of $(R)$-acetoin, which may be due to the complex metabolic network of B. subtilis. Gao et al. reported that whole-cells of recombinant $E$. coli over-expressing DAR could be used to produced relatively high concentration of $(S)$-acetoin $\left(39.4 \mathrm{~g} \mathrm{~L}^{-1}\right)$ from diacetyl. ${ }^{12}$ However, the enantioselective reduction of one diacetyl molecule to form $(S)$-acetoin consumes one NADH/NADPH molecule as an electron

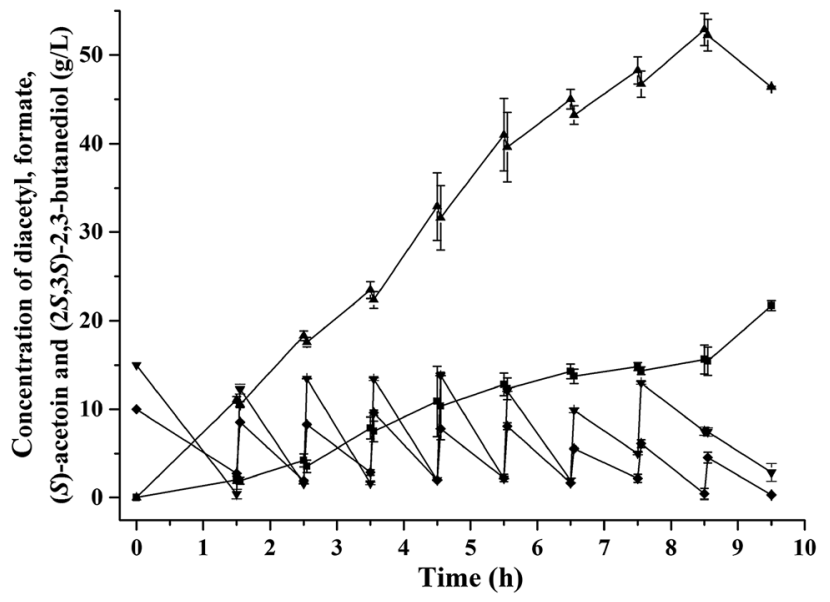

Fig. 4 Production of optical (S)-acetoin by E. coli BL21/pETDuetKpdar-fdh in fed-batch bioconversion. ( $\mathbf{\Delta})(S)$-Acetoin, ( $\mathbf{\square})(2 S, 3 S)$ 2,3-butanediol, ( $\boldsymbol{\nabla}$ ) diacetyl, ( ) formate. Error bars indicate standard deviations $(n=3)$. 
donor, while generating $\mathrm{NAD}^{+} / \mathrm{NADP}^{+}{ }^{+19,39}$ Once the DAR level is no longer limiting, the NADH/NADPH levels become limiting. Thus, it is particularly important to construct an efficient cofactor regeneration system to further increase the productivity.

In the present study, DARs from several species were codonoptimized and compared for $(S)$-acetoin synthesis, and two typical in situ-cofactor regeneration systems were introduced into recombinant $E$. coli. In batch biotransformation, coexpressing KpDAR with FDH resulted in 8.4-fold increase in titer, with enantiomeric purity of $99.6 \%$. Compared with the results achieved previously using glucose as a co-substrate, ${ }^{12}$ coexpressing KpDAR with FDH improved the $(S)$-acetoin concentration from $39.4 \mathrm{~g} \mathrm{~L}^{-1}$ to $52.9 \mathrm{~g} \mathrm{~L}^{-1}$ and productivity from $2.0 \mathrm{~g}$ $(\mathrm{L} \mathrm{h})^{-1}$ to $6.2 \mathrm{~g}(\mathrm{~L} \mathrm{~h})^{-1}$ in fed-batch biotransformation, indicating that the NADH level of $E$. coli was maintained appropriately by introduced FDH regeneration system. Thus, engineering of cofactor regeneration, together with a promising diacetyl reductase, can effectively improve the production of $(S)$ acetoin.

\section{Conclusions}

In this study, we developed an efficient and economical process for high-value chiral $(S)$-acetoin production from diacetyl. Two in situ-NADH regeneration systems were applied to improve the production of $(S)$-acetoin, and five DARs from several species were also compared for $(S)$-acetoin synthesis. Under the optimal conditions, $52.9 \mathrm{~g} \mathrm{~L}^{-1}$ of $(S)$-acetoin was produced with an enantiomeric purity of $99.5 \%$ and a productivity of $6.2 \mathrm{~g}(\mathrm{~L} \mathrm{~h})^{-1}$; the titer and productivity were new records on high optical $(S)$ acetoin (enantiomeric purity $\geq 98.0 \%$ ) production to our knowledge. The systematic approach developed in this study could also be applied to synthesize other optically active $\alpha$ hydroxy ketones.

\section{Conflicts of interest}

There are no conflicts to declare.

\section{Acknowledgements}

This work was supported by the National Natural Science Foundation of China [grant numbers 21466007, 31460296 and 31360207]; and the Guangxi Science and Technology Development Project [grant number 14125008-2-22]. We appreciate the professional comments and the constructive suggestions of the anonymous reviewers and the editor in improving the manuscript.

\section{References}

1 T. Tanaka, M. Kawase and S. Tani, Bioorg. Med. Chem., 2004, 12, 501-505.

2 O. B. Wallace, D. W. Smith, M. S. Deshpande, C. Polson and K. M. Felsenstein, Bioorg. Med. Chem., 2003, 13, 1203-1206.
3 Q. K. Fang, Z. X. Han, P. Grover, D. Kessler, C. H. Senanayake and S. A. Wald, Tetrahedron: Asymmetry, 2000, 11, 3659-3663.

4 G. Song, T. Qin, H. Liu, G. B. Xu, Y. Y. Pan, F. X. Xiong, K. S. Gu, G. P. Sun and Z. D. Chen, Lung Cancer, 2010, 67, 227-231.

5 X. A. Fu, M. X. Li, R. J. Knipp, M. H. Nantz and M. Bousamra, Cancer Med., 2014, 3, 174-181.

6 T. A. Werpy and G. Petersen, Top value added chemicals from biomass: volume I - results of screening for potential candidates from sugars and synthesis gas, US Department of Energy, 2004.

7 Z. J. Xiao and J. R. Lu, Biotechnol. Adv., 2014, 32, 492-503.

8 X. Ji, H. Huang and P. Ouyang, Biotechnol. Adv., 2011, 29, 351-364.

9 T. W. Yang, Z. M. Rao, X. Zhang, M. J. Xu, Z. H. Xu and S. T. Yang, Crit. Rev. Biotechnol., 2017, 37, 990-1005.

10 Q. Xu, L. Xie, Y. Li, H. Lin, S. Sun, X. Guan, K. Hu, Y. Shen and L. Zhang, J. Chem. Technol. Biotechnol., 2015, 90, 93-100.

11 S. Saito, H. Inoue and K. Ohno, EP0409234, EP Patent, 1991.

12 J. Gao, Y. Y. Xu, F. W. Li and G. Ding, Lett. Appl. Microbiol., 2013, 57, 274-281.

13 Y. Peng and S. Z. Chen, Fine Chem. Intermed., 2002, 32, 2021.

14 S. Ui, M. Odagiri, A. Mimura, H. Kanai, T. Kobayashi and T. Kudo, J. Ferment. Bioeng., 1996, 81, 386-389.

15 Z. J. Xiao, P. H. Liu, J. Y. Qin and P. Xu, Appl. Microbiol. Biotechnol., 2007, 74, 61-68.

16 Z. Z. Cui, Y. F. Mao, Y. J. Zhao, C. Chen, Y. J. Tang, T. Chen, H. W. Ma and Z. W. Wang, J. Chem. Technol. Biotechnol., 2018, DOI: $10.1002 /$ jctb.5702.

17 J. Liu, C. Solem and P. R. Jensen, Biotechnol. Bioeng., 2016, 113, 2744-2748.

18 S. Loschonsky, S. Waltzer, B. Volker and P. M. Müller, Chemcatchem, 2014, 6, 969-972.

19 C. Gao, L. Zhang, Y. Xie, C. Hu, Y. Zhang, L. Li, Y. Wang, C. Ma and P. Xu, Bioresour. Technol., 2013, 137, 111-115.

20 Y. He, F. Chen, M. Sun, H. Gao, Z. Guo, H. Lin, J. Chen, W. Jin, Y. Yang, L. Zhang and J. Yuan, Molecules, 2018, 23, 619-634.

21 L. Li, Y. Wang, L. Zhang, C. Ma, A. Wang, F. Tao and P. Xu, Bioresour. Technol., 2012, 115, 111-116.

22 S. Ui, A. Mimura, M. Ohkuma and T. Kudo, Lett. Appl. Microbiol., 1999, 28, 457-460.

23 K. Goldberg, K. Schroer, S. Lütz and A. Liese, Appl. Microbiol. Biotechnol., 2007, 76, 249-255.

24 K. Liang and C. R. Shen, Metab. Eng., 2017, 39, 181-191.

25 Y. Wang, L. Li, C. Ma, C. Gao, F. Tao and P. Xu, Sci. Rep., 2013, 3, 2643.

26 J. Sambrook and D. W. Russell, Molecular Cloning: A Laboratory Manual, Clod Spring Harbor Laboratory, 3rd edn, 2001.

27 Y. J. Zhou, W. Yang, L. Wang, Z. Zhu, S. Zhang and Z. K. Zhao, Microb. Cell Fact., 2013, 12, 1-12.

28 S. J. Bae, S. Kim and J. S. Hahn, Sci. Rep., 2016, 6, 27667. 29 L. Zhang, Y. Y. Xu, J. Gao, H. Xu, C. Cao, F. Xue, G. Ding and Y. Y. Peng, Bioresour. Technol., 2016, 201, 319-328.

30 V. I. Tishkov and V. O. Popov, Biomol. Eng., 2006, 23, 89-110. 
31 N. Samuel, T. Bao, X. Zhang, T. W. Yang, M. J. Xu, X. Li, I. Komera, T. Philibert and Z. M. Rao, J. Chem. Technol. Biotechnol., 2017, 92, 2477-2487.

32 R. Nina, N. Markus, L. Andreas, W. Roland, W. Andrea, E. Thorsten and H. Werner, Biotechnol. Bioeng., 2010, 106, 541-552.

33 A. E. Serov, A. S. Popova, V. V. Fedorchuk and V. I. Tishkov, Biochem. J., 2002, 367, 841-847.

34 J. Z. Lian, R. Chao and H. M. Zhao, Metab. Eng., 2014, 23, 9299.
35 L. Zhang, Y. Zhang, Q. Liu, L. Meng, M. Hu, M. Lv, K. Li, C. Gao, P. Xu and C. Ma, Sci. Rep., 2015, 5, 9033.

36 K. Mädje, K. Schmölzer, B. Nidetzky and R. Kratzer, Microb. Cell Fact., 2012, 11, 1-8.

37 N. Z. Xie, H. Liang, R. B. Huang and P. Xu, Biotechnol. Adv., 2014, 32, 615-622.

38 Z. Liu, J. Qin, C. Gao, D. Hua, C. Ma, L. Li, Y. Wang and P. Xu, Bioresour. Technol., 2011, 102, 10741-10744.

39 M. Takeda, S. Anamizu, S. Motomatsu, X. Chen and C. R. Thapa, Biosci. Biotechnol. Biochem., 2014, 78, 18791886. 